\title{
The Child in the Paediatric Genetics Clinic
}

\author{
Janice McLaughlin, Newcastle University, Newcastle upon Tyne, UK
}

\section{Paper accepted to: eLS}

\section{Advanced article}

\begin{abstract}
:
Children with unexplained problems in their development can be referred to genetics clinics; the number having such referrals is increasing as new technologies enhance the number of genetic variations that can be identified. From the perspective of the child and their family, this raises a number of issues social science research can help us to understand. In particular issues such as understandings of kinship; feelings of parental responsibility; the uncertainties involved in diagnosis, and the different ways the child is visualised through the stages of diagnosis. As new generation sequencing enters the clinic it is important to consider how what happens to children and their families may both change and stay the same.
\end{abstract}

\section{Key words:}

Genetics

Kinship

Diagnosis

Inheritance

Visualisation

New generation sequencing

\section{Key Concepts:}

- Kinship can have both social and biological meaning.

- Parents seek a genetic diagnosis to resolve social as well as medical problems.

- A diagnosis that doesn't provide an answer to what the future holds for a child, or how they should be cared for, may not be seen by parents as a diagnosis.

- Geneticists deploy both interpretative and communicative skills in their interactions with children and their families.

- As new generation sequencing (NGS) enters clinical practice it will generate social and ethical issues.

- A small number of studies of NGS in clinical practice indicate some continuity in the challenges of managing diagnostic uncertainty for both geneticists and families. 


\section{Introduction:}

Children born with a range of developmental problems and unusual physical characteristics, but no clear diagnosis, are increasingly referred to genetics clinics. The diagnostic process begins with dysmorphology (the visual analysis of the child's body aimed at identifying 'abnormal' features) and explorations of family history. It then moves on - over time in a process geneticists refer to as 'watchful waiting' - to analyses of the child's (and sometimes parents') blood. These clinical investigations are not for single gene disorders (such as Downs Syndrome) which are well established, instead paediatric genetics explores less established associations between variations within (deletions) and across (translocations) chromosomes and problems in childhood development. Some of the associations have become established enough to be given a name, others are only referred to via the pattern of chromosomal difference found (for example, '2q37 deletions'). The variations identified can either be inherited or new (referred to as de novo). It is not unusual for the diagnostic outcome to be ambiguous, either because no genetic factor is identified, or because the trait identified does not link to a clinical pathway of treatment or provide a clear indication of what the future holds. The increase in referrals is linked to significant advances in genetic science that have occurred in the last two decades, advances now taking another step forward with the gradual emergence of next generation sequencing (NGS) into clinical practice. See also: DOI: $10.1038 / \mathrm{npg}$. els.0001880; DOI: 10.1002/9780470015902.a0005622.pub3

Social science research has an important role to play in understanding the experiences of families who have a child referred to a genetics clinic. It can help us understand the social and cultural factors that influence people's engagement with it. The central thread across different research is that the process is not a purely medical one; it is also deeply social. This is because people's responses to genetic investigation are influenced by their culturally located understandings of family, by their social contexts such as the care needs of the child, and by their material concerns for what the future holds for their child. In this paper I will highlight important themes within social science research, including my own, which have studied genetic investigations. Understanding better what informs how families respond and what dilemmas they face can help genetics professionals work with them in what can be a challenging process. The paper focuses on 3 themes: what meaning is given to diagnosis, varied understandings of kinship, and the significance of visual techniques within the diagnostic process. The final part of the paper will discuss early findings emerging from social science research of NGS in the paediatric genetics clinic. First, a methodological note about how this research is undertaken.

\section{A Methodological Note}

The majority of the social science research in this area is pursued using qualitative methods that enable a focus on depth and meaning over generalisability. Weight can still be given to the relevance of this research for clinical practice due to the similar themes that emerge across different studies. My own research draws from ethnographic practices of anthropology, but similar approaches are taken in the other studies discussed here. In particular, I and others use non-participant observation (this means that the researcher is present but does not participate in the clinical consultation) to 
capture the detail of the dynamic between geneticist, child patient and other family members. Some researchers also videotape consultations to allow for close analyses of the interactions. The research can also involve a longitudinal element, following the child and family over time. This is particularly important given that diagnosis is rarely immediate, taking repeat consultations and testing to establish a possible answer. Alongside, most studies will include (or at times only involve) interviews with the different actors involved. This can include children (the child referred and/or siblings). Work with children often makes use of specific techniques, such as the child making a journal about their family, to help the process be more meaningful and understandable to them. Figure 1 below is an example of the front cover of a journal made by a young participant in our study.

Figure 1: An example of the front cover of a journal made by a young child (aged 9) who had been referred to a genetics clinic due to developmental delay.

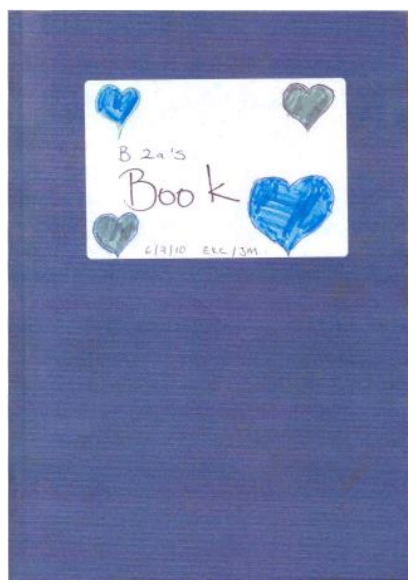

Finally the research data can also involve access to medical records, such as letters explaining a diagnosis. To analyse this range of qualitative data researchers draw from varied conceptual resources, in particular:

- anthropological and sociological work that looks at how family and kinship ties are culturally and socially formed;

- medical sociological work about the social practices involved in diagnostic processes, the organisation of health care, and professional identity;

- disability studies work on the social production of disability and the medical categorisation of differences in body functionality and appearance.

\section{What a Diagnosis Means}

Parents agree to a genetics referral in order to gain a diagnosis. This may seem obvious, but it is important to understand the varied reasons that influence their quest to obtain one. The reasons can include:

- providing an explanation of why their child is not developing well; 
- gaining an indication of what the future holds for their child;

- advice on useful medical treatment;

- obtaining a medical category to help their attempts to receive support for their child from formal support agencies;

- helping them make future reproductive choices.

What is notable about the list is that several factors are oriented towards fixing social problems. Parents, particularly mothers, in our study spoke about wanting a diagnosis in order to stop the questions about what was wrong with their child (McLaughlin and Clavering, 2011). The questions mothers can be asked, by both people they know and strangers in the public sphere, can take the form of blaming the mother for their child's problems (for example, 'why can't you control your child?'). Mothers hope that by being able to give a medical explanation they can avoid such public scrutiny. They also hope that this explanation (much like the popular 'I'm not Naughty I'm Autistic' T-Shirt) will also help their child avoid stigma and discrimination. Seeing diagnosis as a key to getting support for their child speaks to the challenges parents face obtaining appropriate help from medicine, welfare, education and other public bodies. A common theme in research with families with a disabled child is the 'fight' they face to get help; therefore, the hope is that a genetics diagnosis will provide legitimacy to their demands and be a key to unlocking services (McKeever and Miller, 2004; McLaughlin et al., 2008).

How parents respond to a diagnosis - if they receive one - is bound up with the reasons they seek one. From the geneticist's point of view what they are faced with when examining a child with unexplained unusual development traits and physical features is a puzzle. In our work with geneticists and in the genetics literature the common language is that of a puzzle, with the close examination of the child, the taking of the family history, and the varied techniques for examining bloods, providing the clues to aid them solve it. This is understandable given the complexity of making clinical interpretations from the varied pieces of information in front of the geneticist. However, what this also means is that their approach to diagnosis is very different from that of parents. In our study this came across most clearly when diagnoses were provided and communicated to parents (McLaughlin, 2013). Parents spoke of admiring the science that lay behind what the geneticist was able to explain and appreciating having a name (or set of numbers and letters), but equally they spoke of frustration. They stressed that what they needed was something that explained what the future held, but for the most part, because of the rarity of what had been found, or the variety of symptom associated with the genetic variation, or because this was a relatively newly identified variation, this was the one thing the geneticist could not provide. For parents this meant that what geneticists classed as a diagnosis did not feel like a diagnosis to them. A finding that did not come with pointers to treatment or what the future held, was not for them a finding. As other research on paediatric genetics has pointed out it is 'a field of uncertainty' (Latimer, 2007: 99), which families and geneticists must work together to make sense of (Katie Featherstone et al., 2006b). See also: DOI: 10.1002/9780470015902.a0024172

\section{Aspects of Kinship}

First consultations often involve taking a family history, this is the first pointer to the investigation drawing kinship relations into the process. A key theme across studies on 
paediatric genetics is the co-existence of biological and social understandings of family (Featherstone et al., 2006a; Fitzgerald, 2008; Latimer, 2013) within the diagnostic process. As Atkinson et al. (2001: 21) argue 'The 'natural' facts of biological relations and the 'social facts' of kinship are brought together through the everyday work and talk of specialists'. A family's history is used by geneticists to see if there is any pattern of health problems in the family that could help them solve their puzzle. Therefore the family 'pedigree' is a picture of the biological connections between individuals and the patterns of ill heath they share. As Featherstone et al. point out: 'The family-in-thelaboratory is constructed through successive iterations of biological testing and the tracing of shared physical characteristics' (2006a: 41). This is a very different understanding of what family means for people generally. Social anthropology (Carsten, 2004; Carsten, 2000) and sociology of family (Morgan, 1996) have done much to show how people live with a range of understandings of what family is. They may draw from biology to explain who is their kin, but they also are influenced by cultural understandings that can bring others into their conception of who counts as family (sometimes referred to as 'fictive kin' (Weeks et al., 2001)), while at the same time placing others who are biologically related outside. This understanding of family produces a range of responses to the questions raised about family relationships within the diagnostic process.

It can be disquieting to find family histories, which previously had been surrounded by secrecy or sorrow, opened up to scrutiny. One mother in our study spoke of being unable to go back in her family history beyond her own mother, because her mother's parents had both killed themselves. This was a painful history that neither she nor her mother wanted to return to (McLaughlin and Clavering, 2011). Another mother refused to contact her estranged father to see if he would be willing to give blood to help the investigation; this was because maintaining the broken social tie to her father was more important than establishing the character of the biological tie between grandfather and child (McLaughlin, 2015). The biomedical focus of the geneticist can also run counter to the way in which people value their familial ties. Inherited genetic traits often run down the maternal or paternal line. This can generate a variety of issues. Mothers in particular can feel a sense of guilt or responsibility if the trait has come through their blood line. One mother spoke about how she had keep her child away from her biological kin whose behaviour and attitudes she found problematic (toxic was the word she used). She therefore found it very upsetting to be told that her child's problems had been passed down the maternal line (McLaughlin, 2015). From her perspective all her work to protect her child had been undermined because a permanent connection had been made between her son and her biological kin that she could not remove or repair. This is a key reason why a de novo explanation is often preferred as it alleviates this sense of guilt (Dimond, 2014a). Indeed one of the forms of 'moral labour' geneticists do when communicating a de novo explanation is to stress that it means that parents should not blame themselves, either for passing this on, or doing anything in the pregnancy that could have contributed to the problem (Featherstone et al., 2006b).

However, this does not mean that parents always experience being told they are not the source of a child's problem positively. We were powerfully struck by the hurt one father felt at not being included in his daughter's family pedigree ('I wasn't there'). The reason he was not included was because the geneticist was sure the issue lay in the maternal line. In response the father stressed the ways in which the daughter did take after him 
(McLaughlin and Clavering, 2012). For example, he spoke of both of them being short, even though short stature was something the geneticist was associating with the maternal trait they were investigating.

A final aspect of the complex relationship between different understandings of family and people's responses to genetic investigation is the importance of notions of similarity and difference to the formation of kinship ties. While a geneticist looks for patterns of difference to support a diagnosis of genetic mutation, these same traits of difference can, from the family's perspective, be something they share and which makes them similar. Strangely shaped ears or particular behavioural traits can be an indication of belonging and with that normality. One young girl was told she had the same genetic trait as her mother, which was the reason both had learning disabilities. She explained to us that this made her happy, because it meant they 'were the same'.

\section{Visualising the Child}

Medical sociology has a long term fascination with the role of the visual within medicine. Whether this be the medical gaze, which Foucault (1975) argued established the power of the clinician, or new debates about the move from gazing on the body, to gazing on the digital representation (Navon, 2011). Work on paediatric genetics is an important field where debates about the significance of the visual in contemporary medicine are being played out (Featherstone et al., 2005; Verhoeff, 2012).

The child is visualised in a number of ways across genetic investigations. First is the very close physical examination by the geneticist, something which can happen repeatedly as the child gets older. Second, photographs are taken to study the child over time and for geneticists to share with others in research papers or in clinic group discussions. Third, are the computer generated images of chromosomes and genes that geneticists produce to help their diagnosis and to communicate that diagnosis to parents. These different visualisations become embedded with varied meanings. Geneticists work very carefully to try to ensure that the close examination of the child does not make the child or other family members present feel uncomfortable. As Latimer (2007) argues there is a strong recognition that this process could objectify the child and emphasise the sense that they are different. This can include other family members present, we have witnessed other family members examining themselves as geneticists point out webbed fingers or unusual head sizes. Geneticists try to minimise objectification by the way they talk to the child, asking for their approval to do the things they are doing, by often getting down on their hands and knees to be at the height of the child, rather than make the child sit on a bed. They also speak in everyday language and stress all the things they see in the child that are 'normal', alongside stressing how much we all have genetic variation within us. Nevertheless it is hard for the parents to not see the process as one that turns their child into an object of medical curiosity and this feeling can grow over time if no diagnosis is forthcoming (McLaughlin and Clavering, 2012).

The internet is full of images of children with particular genetic traits. Geneticists often warn of the risks of looking on the internet, but as with other health conditions, it is inevitable that people turn to the internet when a possible diagnosis is raised. It is the images they find of other children that generate the strongest reactions, sometimes 
positive, sometimes negative. Seeing a clinical history linked to a child who looks very much like their child can give a sense of certainty to what the future holds for their child (Whitmarsh et al., 2007). If the history is positive this can be very reassuring, if it is negative it can be deeply worrying. In addition, physical similarity is something culturally significant to senses of connection and belonging. This is why parents can be reassured by seeing pictures online of children who look like their child. Parents talked of finding new communities of belonging through the visual recognition they saw in virtual displays.

As noted above as the diagnosis progresses the gaze moves from the child to computer diagrams of chromosomes and genetic markers. A common theme in social science research is that genetics represents the 'geneticisation of life' (Finkler, 2001; Novas and Rose, 2000). Computer generated images of DNA are seen as evidence of that process, replacing the living body with a representation; a representation which is more important to diagnosis. This led Raspberry and Skinner (2007) to ask: are we moving to a point where the body becomes text? The concern of researchers is that a child can be diagnosed with a disorder due to how a diagram is read, rather than the existence of symptoms of illness. Buchbinder and Timmermans (2011: 57) have spoken of such diagnoses as 'ontologically disputed borderline forms of disease' and Featherstone et al. (2005: 557) refer to them as 'genetic syndromes... in the making'. Another concern is that the interpretative skill of the geneticist to connect family histories, to the clues displayed in the body, and to biochemical analyses will become less important than what the DNA diagram appears to indicate. We seem some way from these concerns becoming a reality.

Parents know a diagram is not their child, they can find a fascination with it and the odd sequence of numbers and letters it displays, but this does not mean it carries the same meaning as their living child (McLaughlin, 2013). The disorders these diagrams display are so rare and uncertain in meaning that it is also difficult to see how on their own they can create disorder where there is none. Indeed parents in our study spoke of their frustration that when they shared a diagnosis with others, either family, or other medical professionals, that it meant very little to them. As a result they often went back to using phrases such as 'global developmental delay'. Family members, including the child themselves, as other researchers such as Dimond (2014b), Fitzgerald (2008), Latimer (2013) and Raspberry and Skinner (2007) have argued, are not passive dupes straightforwardly absorbing genetic understandings of family; instead they are involved in exchanges across different understandings and values. Finally, we also seem some way off from the geneticist becoming an unskilled production worker relaying what the biochemical analyses and complex computations have produced as 'the answer'. Interpretative skill remains at the heart of the 'diagnostic odyssey'. Arguments about the loss of clinical professional skill also miss an important part of the geneticist tool kit, which the research of Featherstone et al. (2006b) capture very well. They argue that geneticists perform 'moral labour' when their communication approach emphasises the normality of the child and the lack of responsibility parents should feel, regardless of whether an inherited or de novo trait is found. Whether we should remain sceptical of the diagram's capacity to replace both the child and the geneticist from diagnosis depends a great deal on what happens when NGS becomes the norm in the paediatric genetics clinic. 


\section{New Generation Sequencing}

NGS is the next advance in genetic investigation (Anderson et al., 2017; Biesecker and Green, 2014). It is a variety of techniques that enable closer and broader analysis of the human genome, meaning that a far greater number of variants in any one person can be identified. As the majority of Global North countries commit to bring NGS into healthcare delivery, a range of social and ethical dilemmas are being raised (ACMG, 2015; Anderson et al., 2017; Sabatello and Appelbaum, 2015),. So far the main technique being used is exome sequencing, this focuses on 'the protein coding regions that constitute only one per cent of the human genome, but harbour the deleterious variants that cause the vast majority of Mendelian diseases' (Skinner et al., 2016: 1303). On the face of it this could imply a very different process of genetic investigation than currently present. One that is marked by greater certainty and less interpretative skill by the geneticist. Research studies of its use in paediatric genetics are only starting to be published. What they are showing so far is important areas of continuity with the current picture. See also: DOI: 10.1002/9780470015902.a0025838; DOI: 10.1002/9780470015902.a0022508; DOI: 10.1002/9780470015902.a0022483; DOI: 10.1002/9780470015902.a0005620.pub2

Stivers and Timmermans (2017), in a study of families receiving a diagnosis that was a result of exome sequencing, found that parents experienced a similar pattern of fascination with the technology, while simultaneously feeling disappointment about what it could tell them that could be useful for planning for the future and battling with services. Given NGS will be finding new traits with little or no clinical history associated with them for some time, the dynamic of uncertainty and ambiguity families currently face is unlikely to diminish, indeed it is more likely to increase. This points to one of the key debates regarding NGS: what value does identifying a particular genetic variant need to have to warrant its disclosure (Wouters et al., 2017)? Ethicists and geneticists are particularly exercised by what constitutes utility; not only which form of utility is it that matters - clinical or social - but also what constitutes clinical and social utility in the first place (Bush, 2014; PHG Foundation, 2011). There is also much discussion of whose interests should inform disclosure - the best interests of the child or their broader family, or both (Kleiderman et al., 2014)? Stivers and Timmermans also found, as is the case now, that interpretative skill remains central to the diagnosis process - not only the interpretative skill of the individual geneticist, but also the community of geneticists who are drawn into the investigation. Finally, they argue that the geneticist still needs to have the communicative skills to respond to parental feelings of responsibility.

Skinner et al. (2016) have also undertaken a study of a clinic using exome sequencing, finding similar themes about the continued role of interpretative and communicative skills in the interaction between geneticist, child and other family members. They argue that a high level of interpretative skill remains, with considerations of family history still playing a role in judgements about whether a variation found can be clinically significant. They also stress that continued uncertainties remain, both in terms of what the meaning and value of the traits found are, and also that a significant number of families will leave still with no diagnosis. They argue that geneticists manage the risks of negative diagnosis by stressing that it leaves open the possibility that in the future a diagnosis may become possible, they simply haven't found it yet, as such 'the negative result 
becomes a referent not only for uncertainty but also for the potential of future definitive outcomes' (2016: 305).

\section{Conclusion}

Paediatric genetics is a complex space where social and medical worlds come together to shape meaning. It is also a space where significant uncertainty unfolds both in attempts to diagnose a child and to take meaning and action from anything found. Parents and children are active participants in the processes, working with geneticists to share relevant family histories and making sense of a diagnosis. The relationship between geneticist, patient and family remains important; with the geneticist required to enact a range of both interpretative and communicative skills. The introduction of NGS will change some of these interactions and relationships, but we seem some way off from uncertainty being lost and genetics defining who we are over other understandings of what makes us normal or different as an individual or as a family.

\section{Acknowledgements}

Much of the research summarised here came from the following Economic and Social Research Council project: 'Kinship and genetic journeys: A study of the experiences of families who are referred to paediatric genetics', PI: Janice McLaughlin, CIs: Professor Erica Haimes, and Dr Michael Wright, RES-062-23-1475.

\section{References}

ACMG (2015) Clinical utility of genetic and genomic services: a position statement of the American College of Medical Genetics and Genomics. Genetics in Medicine. 17: 505-507.

Anderson, JA, Meyn MS, Shuman C et al. (2017) Parents perspectives on whole genome sequencing for their children: qualified enthusiasm? Journal of Medical Ethics. 43(8): 535-539.

Atkinson P, Parsons E and Featherstone K (2001) Professional constructions of family and kinship in medical genetics. New Genetics and Society. 20(1): 5-24.

Biesecker LG and Green RC (2014) Diagnostic clinical genome and exome sequencing. New England Journal of Medicine. 370(25): 2418-2425.

Buchbinder M and Timmermans S (2011) Medical technologies and the dream of the perfect newborn. Medical Anthropology. 30(1): 56-80.

Bush L (2014) In the best interest of the child: psychological and ethical reflections on traditions, contexts, and perspectives in pediatric clinical genomics. American Journal of Bioethics. 14(3): 16-18.

Carsten J (2004) After Kinship. Cambridge: Cambridge University Press.

Carsten J (ed) (2000) Cultures of Relatedness. Cambridge: Cambridge University Press.

Dimond R (2014a) Negotiating blame and responsibility in the context of a "de novo" mutation. New Genetics and Society. 33(2): 149-166.

Dimond R (2014b) Negotiating identity at the intersection of paediatric genetic medicine: the parent as facilitator, narrator and patient. Sociology of Health \& IIIness. 36(1): 1-14.

Featherstone K, Atkinson P, Bharadwaj A et al.(2006a). Risky Relations: Family Kinship and the New Genetics. Oxford: Berg. 
Featherstone $\mathrm{K}$, Gregory $\mathrm{M}$, and Atkinson $\mathrm{P}$ (2006b) The moral and sentimental work of the clinic, In: Atkinson P, Glasner P and Greenslade H (eds) New Genetics, New Identities, pp. 101-119. London: Routledge.

Featherstone K, Latimer J, Atkinson P et al. (2005) Dysmorphology and the spectacle of the clinic. Sociology of Health \& IIlness. 27(5): 551-574.

Finkler K (2001) The kin in the gene - The medicalization of family and kinship in American society. Current Anthropology. 42(2): 235-263.

Fitzgerald R (2008) Biological citizenship at the periphery: parenting children with genetic disorders. New Genetics and Society. 27(3): 251-266.

Foucault M (1975) The Birth of the clinic. New York, NY: Vintage Books.

Kleiderman E, Knoppers BM, Fernandez CV et al. (2014) Returning incidental findings from genetic research to children: views of parents of children affected by rare diseases. Journal of Medical Ethics. 40(10): 691-696.

Latimer J (2007) Diagnosis, dysmorphology, and the family: Knowledge, motility, choice. Medical Anthropology. 26(2): 97-138.

Latimer J (2013) The Gene, The Clinic and the Family. London: Routledge.

McKeever P and Miller KL (2004) Mothering children who have disabilities: a Bourdieusian interpretation of maternal practices. Social Science \& Medicine. 59(6): 1177-1191.

McLaughlin J (2014) Digital imagery and child embodiment in paediatric genetics: Sources and relationships of meaning. Sociology. 48(2): 216-232.

McLaughlin J (2015) Family ties in genes and stories: The importance of value and recognition in the narratives people tell of family. The Sociological Review. 63(3): 626-643

McLaughlin J and Clavering EK (2011) Questions of kinship and inheritance in pediatric genetics: substance and responsibility. New Genetics and Society. 30(4): 399413.

McLaughlin J and Clavering EK (2012) Visualising difference, similarity and belonging in paediatric genetics. Sociology of Health and Illness. 34(3): 459-474.

McLaughlin J, Goodley D, Clavering EK et al. (2008) Families Raising Disabled Children: Enabling Care and Social Justice. Basingstoke: Palgrave Macmillan.

Morgan D (1996) Family Connections. Cambridge: Polity Press.

Navon, D (2011) Genomic designation: How genetics can delineate new, phenotypically diffuse medical categories. Social Studies of Science. 41(2): 203-226.

Novas C and Rose N. (2000). Genetic risk and the birth of the somatic individual. Economy and Society. 29(4): 485-513.

PHG Foundation (2011) Next steps in the sequence: The implications of whole genome sequencing for health in the UK. Cambridge: PHG Foundation.

Raspberry K and Skinner D (2007) Experiencing the genetic body: Parents' encounters with pediatric clinical genetics. Medical Anthropology. 26(4): 355-391.

Sabatello M and Appelbaum PS (2015) Honey, I sequenced the kids: preventive genomics and the complexities of adolescence. American Journal of Bioethics. 15(7): 19-21.

Skinner D, Raspberry KA and King M (2016) The nuanced negative: meanings of a negative diagnostic result in clinical exome sequencing. Sociology of Health \& Illness. 38(8): 1303-1317.

Stivers T and Timmermans S (2017) The actionability of exome sequencing testing results. Sociology of Health \& Illness. 39(8): 1542-1556.

Verhoeff B (2012) What is this thing called autism? A critical analysis of the tenacious search for autism's essence. Biosocieties. 7(4): 410-432.

Weeks J, Heaphy B and Donovan C (2001) Same Sex Intimacies: Families of Choice and Other Life Experiments. London: Routledge.

Whitmarsh I, Davis AM, Skinner D and Bailey DB (2007) A place for genetic uncertainty: parents valuing an unknown in the meaning of disease. Social Science \& Medicine. 65: 1082-1093. 
Wouters RHP, Cornelis C, Newson AJ et al. (2017) Scanning the body, sequencing the genome: Dealing with unsolicited findings. Bioethics. 31(9): 648-656.

\section{Further Reading:}

Blum LM (2007) Mother-blame in the prozac nation - Raising kids with invisible disabilities. Gender \& Society. 21(2): 202-226.

Cox SM and McKellin W (1999) 'There's this thing in our family': predictive testing and the construction of risk for Huntington Disease. Sociology of Health \& Illness. 21(5): 622-646.

Franklin S and McKinnon S (2001) (eds) Relative Values: Reconfiguring Kinship Studies. Durham, NC: Duke University Press.

McLaughlin J (2005) Exploring diagnostic processes: social science perspectives. Archives of Diseases in Childhood, March(90): 284 - 287.

Rose N (2006) The Politics of Life Itself: Biomedicine, Power, and Subjectivity in the Twenty-First Century. Princeton, N.J.: Princeton University Press.

Smart C (2011) Families, secrets and memories. Sociology. 45(4): 539-553. 